\title{
EPR and UV-Vis Spectroscopic Studies of the Influence of Ultraviolet Irradiation on Antioxidant Interactions of Nystatin
}

\author{
Paweł Ramos*, Barbara Pilawa, Piotr Pepliński \\ School of Pharmacy with the Division of Laboratory Medicine in Sosnowiec, Medical University of Silesia in Katowice Department of \\ Biophysics, Jedności, Sosnowiec, POLAND.
}

\begin{abstract}
The changes of the free radical scavenging activity of nystatin after UV-irradiation were examined. The kinetics of the interactions of nystatin with free radicals was tested. The model DPPH free radicals were used. Free radicals were tested by an X-band $(9.3 \mathrm{GHz})$ electron paramagnetic resonance spectroscopy. The EPR spectra of DPPH and DPPH in contact with non-irradiated and UV-irradiated nystatin were measured. Nystatin quenched the EPR spectra of DPPH free radicals as the result of the antioxidative character of the samples. The antioxidative character of non-irradiated and UV-irradiated nystatin was confirmed by the UV-Vis studies. Free radical scavenging activity decreased after UV-irradiation of nystatin and the EPR spectra of DPPH free radicals lower decreased by contact with UV-irradiated nystatin. The quenching of UV-Vis spectra were lower for UV-irradiated nystatin than for than with non-irradiated drug. It was pointed out that nystatin should not be storage under ultraviolet irradiation, because of decrease its antioxidative interactions. This studies confirmed usefulness of EPR spectroscopy and UV-Vis spectrophotometry to determine of the antioxidant character of drugs. These spectroscopic methods may be used to find the optimal storage conditions of drugs.
\end{abstract}

Key words: Nystatin, Antioxidant, UV-irradiation, EPR, UV-Vis.

\section{INTRODUCTION}

Antioxidants protect the human organism against free radicals. ${ }^{1-4}$ Free radicals as the molecules with unpaired electrons may be the source of the chain reactions, which destroy the cellular structures. ${ }^{5-9}$ A lot of pathological states in the organism are accompanied by free radicals formation. ${ }^{5-9}$ Inflammatory states are typically linked with mycosis. ${ }^{10,11}$ Free radicals are produced during the inflammation process, ${ }^{7-9}$ so the interactions with free radicals for drugs applied in the illness accompanied by inflammation states are the important problem. In this work the interactions with free radicals for nystatin, one of the antifungal drug, ${ }^{12,13}$ were examined by the use of spectroscopic methods. The antioxidant properties of other antifungal agents such as ketoconazole, ${ }^{14}$ benzimidazole ${ }^{15}$ and nystatin by incorporation into lipid nanocarriers ${ }^{16}$ are known. Chemical structure of nystatin was presented in Figure $1 .{ }^{17}$

The aim of this work was to check the antioxidative character of nystatin and to determine the influence of ultraviolet irradiation on the free radical scavenging activity of nystatin. The interactions of nystatin with free radicals for non-irradiated and UV-irradiated samples were examined, to obtain the influence of UV-irradiation on free radical scavenging activity of nystatin. The negative effect of UV-irradiation on solutions containing nystatin is known. ${ }^{18}$ The practical application of this studies is to get information about the storage condition of nystatin. The tested antibiotic should be storage without UV-radiation when these electromagnetic waves decrease its interactions with free radicals. Nystatin may be
Submission Date: 16-12-2017; Revision Date: 14-08-2018; Accepted Date: 22-01-2019.

DOI: 10.5530/ijper.53.2s.65 Correspondence: Dr. Pawet Ramos, School of Pharmacy with the Division of Laboratory Medicine in Sosnowiec, Medical University of Silesia in Katowice Department of Biophysics, Jedności 8, 41-200 Sosnowiec,

POLAND.

Phone: +48-323641162 E-mail: pawelramos@sum. edu.pl

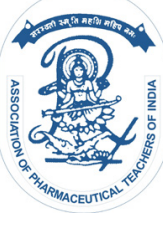

www.ijper.org 


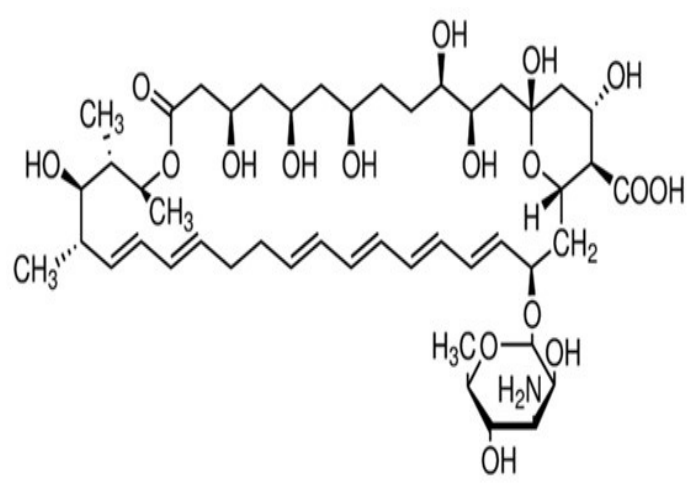

Figure 1: Chemical structures of nystatin. ${ }^{17}$

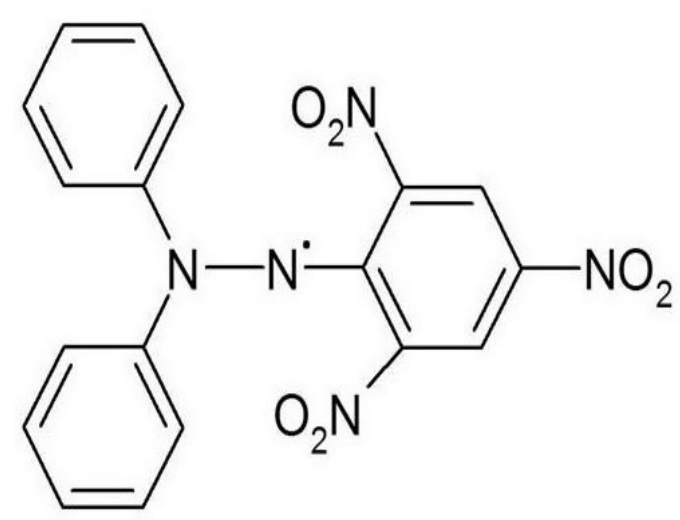

Figure 2. Chemical structure of DPPH (2,2-difenyl-1-picrylhydrazyl). Unpaired electron was signed as (•) [Tirzitis et al, 2010].

exposed to UV-radiation, when it does not modify the antioxidative interactions of this antiobiotic.

The electron paramagnetic resonance (EPR) spectroscopy was used to check if the nystatine samples interact with free radicals. The interactions of the antioxidative substances with free radicals quench the EPR lines of free radicals. ${ }^{19}$ The UV-Vis spectrophotometry was also used in observations of the antioxidative interactions of the nystatin samples. The model DPPH (2,2-difenyl1-picrylhydrazyl) free radicals ${ }^{9,20-23}$ were used in our studies. The chemical structure of DPPH free radical molecule with unpaired electron localized on nitrogen $(\mathrm{N})$ atom was shown in Figure $2 .^{20}$

These spectroscopic EPR and UV-Vis studies of the influence of ultraviolet irradiation on interactions of nystatin with the model free radicals are innovatory. The performed experiment broaden our knowledge about antioxidative character of nystatin and it indicate the storage condition of this drug.

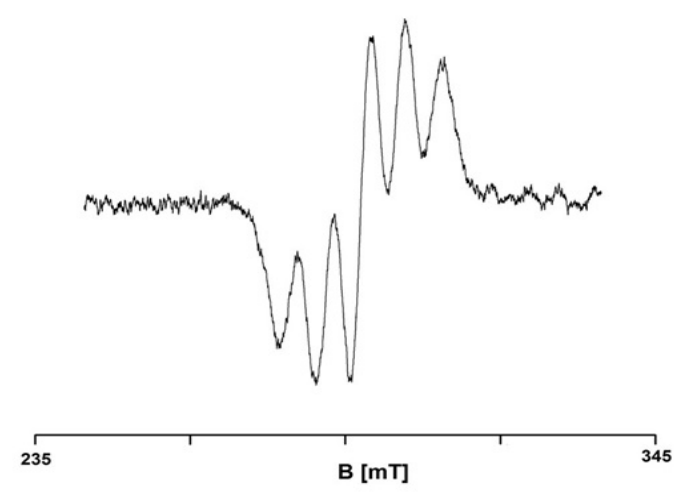

Figure 3: EPR spectrum of DPPH in (96\%) ethyl alcohol solution. B - magnetic induction.

\section{MATERIALS AND METHODS UV irradiation of nystatin}

Nystatin was irradiated by Medisun 250 lamp (Germany) with 4 radiators with power of $20 \mathrm{~W}$. UVA radiation with the wavelengths $(\lambda)$ in the range of $315-400 \mathrm{~nm}$ was emitted to this drug during $30 \mathrm{~min}$. The distance between the lamp and the drug sample was $30 \mathrm{~cm}$.

\section{EPR measurements}

The antioxidant interactions of nystatin were examined by the use of two spectroscopic methods: EPR and UV-Vis. DPPH (2,2-difenyl-1-picrylhydrazyl) was used as the reference of free radicals. The free radical scavenging activity of nystatin was determined by the electron paramagnetic resonance measurements of the quenching of DPPH free radicals EPR spectra after addition of the tested antibiotic to DPPH the ethyl alcohol solution. The reference ethyl alcohol solution $(96 \%)$ of DPPH was prepared. The EPR spectrum of DPPH free radicals in the reference solution was shown in Figure 3.

The non-irradiated and UV-irradiated nystatin samples were added to this solution. EPR measurements were performed for the solutions located in the thin walled glass tubes with the external diameter of $1 \mathrm{~mm}$. The EPR signals of the empty tubes were not observed at the experimental conditions. EPR spectrum of DPPH in the reference ethyl alcohol solution was measured. After the EPR spectra of DPPH interacting with the nystatin samples in the ethyl alcohol solution were obtained. The EPR spectra of the DPPH in contact with non-irradiated and UV-irradiated nystatin were compared with the EPR line of the reference solution of DPPH. The antioxidative interactions were determined as the DPPH free radicals scavenging. The free radical scavenging activity revealed as the quenching of the EPR spectrum of DPPH. 
EPR measurements were performed at room temperature by the use of an X-band $(9.3 \mathrm{GHz})$ electron paramagnetic resonance spectrometer with magnetic modulation of $100 \mathrm{kHz}$ produced by Radiopan Firm (Poznań, Poland). The numerical acquisition of data was done by use of the Rapid Scan Unit of Jagmar Firm (Kraków, Poland), which was linked to the spectrometer. The total microwave power produced by klystron was $70 \mathrm{~mW}\left(\mathrm{M}_{\mathrm{o}}\right)$. Microwave frequency was directly obtained by MCM101 recorder of EPRAD Firm (Poznań, Poland). The kinetics of interactions of the nystatin samples was obtained from the EPR spectra of DPPH free radicals detected by 1 min intervals up to $21 \mathrm{~min}$. The EPR spectra were recorded as the firstderivative lines. To avoid microwave saturation the EPR spectra of DPPH free radicals were measured with the low microwave power of $2.2 \mathrm{~mW}$, which corresponded to attenuation of $15 \mathrm{~dB}$. The microwave power used during the EPR measurements $(\mathrm{M})$ was obtained from the following formula: ${ }^{24}$

$$
\text { attenuation }[\mathrm{dB}]=10 \lg \left(\mathrm{M} / \mathrm{M}_{\mathrm{\alpha}}\right)
$$

EPR measurements and analysis of the recorded spectra were done by the use of professional spectroscopic programs of Jagmar Firm (Kraków, Poland), LabView (National Instruments, USA) and Origin (OriginLab, USA).

For the EPR spectra of DPPH drugs in ethyl alcohol solution before and after addition of the nystatin samples (nonirradiated and UV-irradiated) amplitudes (A) were determined. Amplitudes (A) of EPR spectra of DPPH in contact with the tested samples were divided by the amplitude (A) of DPPH - in the reference solution. Correlations between amplitudes (A) [ \pm 0.02 a.u.] of $\mathrm{DPPH}$ line and the time $(\mathrm{t})$ of its interactions with the nystatin samples were determined. The influence of UV-irradiation of nystatin on the kinetics of its interactions with DPPH free radicals was obtained.

g-Factor [ \pm 0.0002$]$ for DPPH EPR lines was calculated from the resonance formula as: $:^{24-26}$

$$
\mathrm{g}=\mathrm{h} \nu / \mu_{\mathrm{B}} \mathrm{B}_{\mathrm{r}}
$$

where:

$$
\begin{aligned}
& \mathrm{h}-\text { Planck constant, } \\
& \nu-\text { microwave frequency, } \\
& \mu_{\mathrm{B}}-\text { Bohr magneton and } \\
& \mathrm{B}_{\mathrm{r}}-\text { induction of resonance magnetic field. }
\end{aligned}
$$

Thermo Genesis 10S UV-Vis spectrophotometer produced by Thermo Scientific Firm (USA) was also used in this study. Ethyl alcohol solution of DPPH and nystatin in a concentration $5 \%$ was prepared. The absorption spectra of DPPH in the wavelength range of $\lambda$ : 400-780 $\mathrm{nm}$ for contact with the non-irradiated and UV-irradiated nystatin samples in ethanol solution were obtained. The individual measurement was zeroed on ethyl alcohol. The changes in the absorbance of DPPH during interactions with the non-irradiated and UV-irradiated nystatin samples were determined.

\section{RESULTS AND DISCUSSION}

Electron paramagnetic resonance measurements pointed out that nystatin interacts with DPPH free radicals. The free radical scavenging activity was observed for both non-irradiated and UV-irradiated samples. EPR lines of DPPH free radicals were quenched after addition of nystatin to the ethyl alcohol solution. The quenching of the EPR spectra of DPPH free radicals during interactions with non-irradiated nystatin was presented in Figure 4 a. The decrease of the EPR spectra of DPPH free radicals during interactions with UV-irradiated nystatin was presented in Figure 4 b.

The kinetics of the interactions of non-irradiated and UV-irradiated nystatin was similar. The changes of amplitudes (A) of the EPR spectra of DPPH free radicals with increasing of interaction time $(t)$ for nonirradiated and UV-irradiated nystatin, were presented in Figure $5 \mathrm{a}$ and Figure $5 \mathrm{~b}$, respectively. Amplitude (A) of the measured EPR lines decreased with increasing of time, its values reached the minimum and after the amplitudes (A) did not changed with time of interactions. The stabilization of interactions of non-irradiated (Figure 5 a) and UV-irradiated (Figure 5 b) nystatin samples with DPPH free radicals stabilized after $12 \mathrm{~min}$. The minimal values of amplitudes $\left(\mathrm{A}_{\text {min }}\right)$ for $\mathrm{DPPH}$ free radicals interacting with non-irradiated and UV-irradiated nystatin were compared in Figure 6. Their values were related to the amplitude of the line of DPPH free radicals in the reference solution. Both non-irradiated and UV-irradiated nystatin samples quenched DPPH free radicals (Figure 6). The free radicals scavenging activity was decreased after UV-irradiation of nystatin. (Figure 6). So it can be say that nystatin should be storage in dark without ultraviolet exposition. UV-irradiation decreased antioxidative interactions of nystain.

The results obtained by the use of EPR spectroscopy were confirmed by UV-Vis measurements for the nonirradiated and UV-irradiated nystatin. The absorbance spectra for the nystatin before and after UV-irradiation, were shown in Figure $7 \mathrm{a}$ and Figure $7 \mathrm{~b}$, respectively. The UV-Vis spectra of DPPH were quenched by both non-irradiated and UV-irradiated nystatin. UV-Vis 

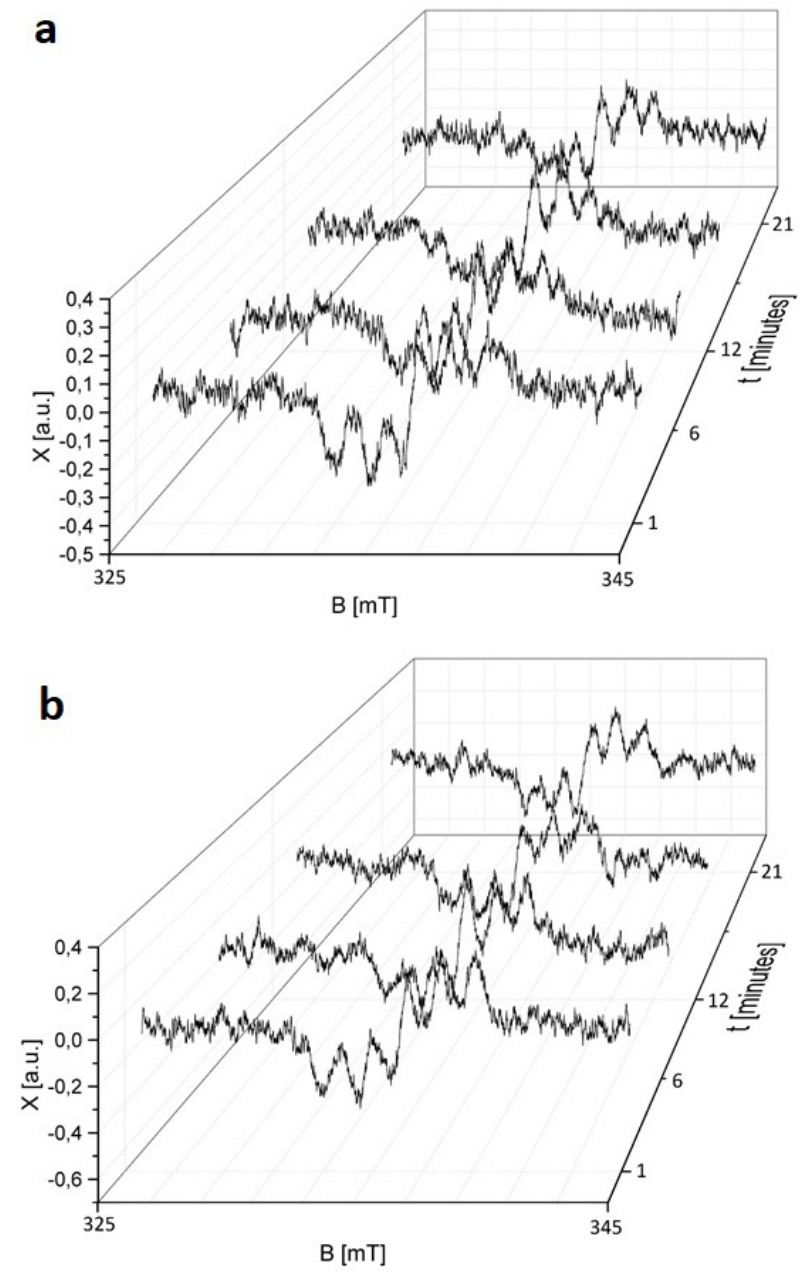

Figure 4: EPR spectra of DPPH interacting with (a) nonirradiated and (b) UV-irradiated nystatin during $1 \mathrm{~min}, 6 \mathrm{~min}, 12 \mathrm{~min}$ and $21 \mathrm{~min}$. B - magnetic induction.

examination confirmed the antioxidative character of nystatin.

The kinetics of interactions of the non-irradiated and UV-irradiated nystatin samples with DPPH, was compared in Figure 8 a and Figure 8 b, respectively. The maximal absorbance of the UV-Vis spectra decreased with increasing time of interactions and after then it reached the stable value. The minimal values of the maximal absorbance of the UV-Vis spectra for nonirradiated and UV-irradiated nystatin samples were compared in Figure 9. Similar to the EPR results (Figure 6), the quenching of DPPH (Figure 9) characterized the two tested samples. The quenching of the UV-Vis spectra (Figure 9) similar to the EPR spectra (Figure 6) was weaker for the UV-irradiated nystatin. But the differences for the non-irradiated and UV-Vis irradiated nystatin, between the amplitude vales of UV-Vis spectra in Figure 9 were lower than for the EPR spectra in Figure 6. UV-Vis measurements confirmed a

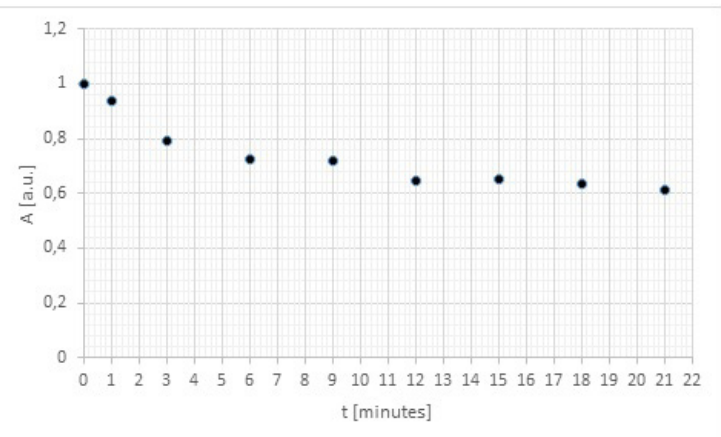

b

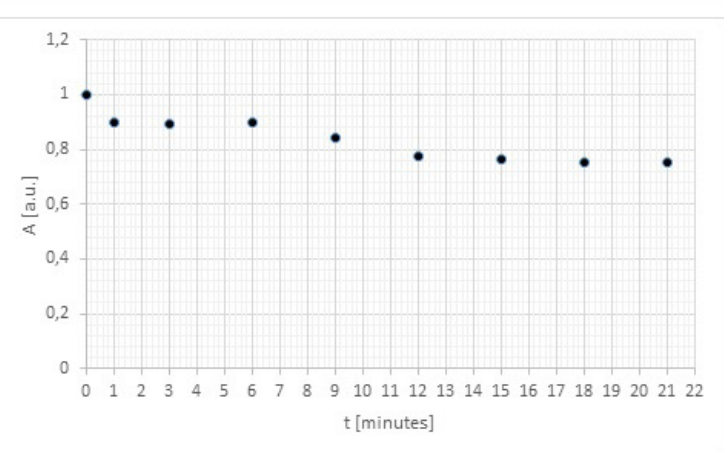

Figure 5: The influence of time (t) of interactions on amplitudes (A) of EPR lines of DPPH in contact with (a) nonirradiated and (b) UV-irradiated nystatin.

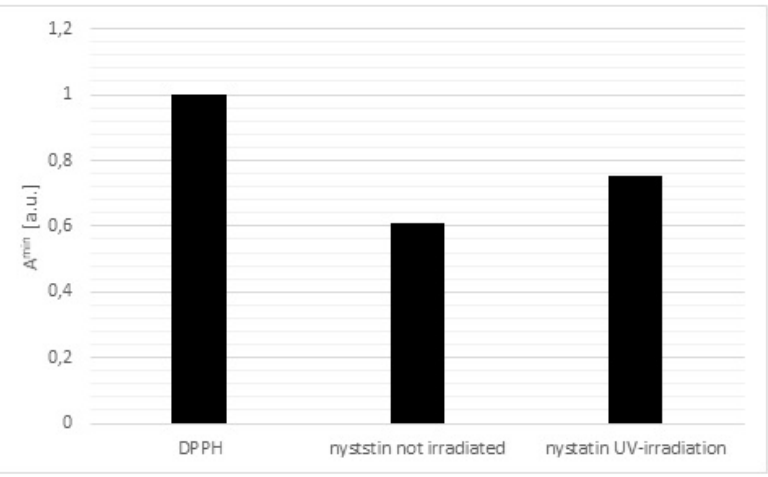

Figure 6: Comparison of the minimal amplitudes $\left(A_{\min }\right)$ of DPPH lines for DPPH interacting with non-irradiated and UVirradiated nystatin. The amplitude of DPPH in the reference solution was shown.

the relation that the antioxidative interactions of the nystatin exposed to UV-irradiation was lower than for non-irradiated nystatin. The results indicates that EPR method was the higher sensitive for the observation of the antioxidative interactions than the UV-Vis method.

EPR spectroscopy and UV-Vis spectrophotometry were the useful methods to examine antioxidative interactions of nystatin. These methods give information about the kinetics and the values of interactions of the drug with model free radicals. ${ }^{27-29}$ The results may be 

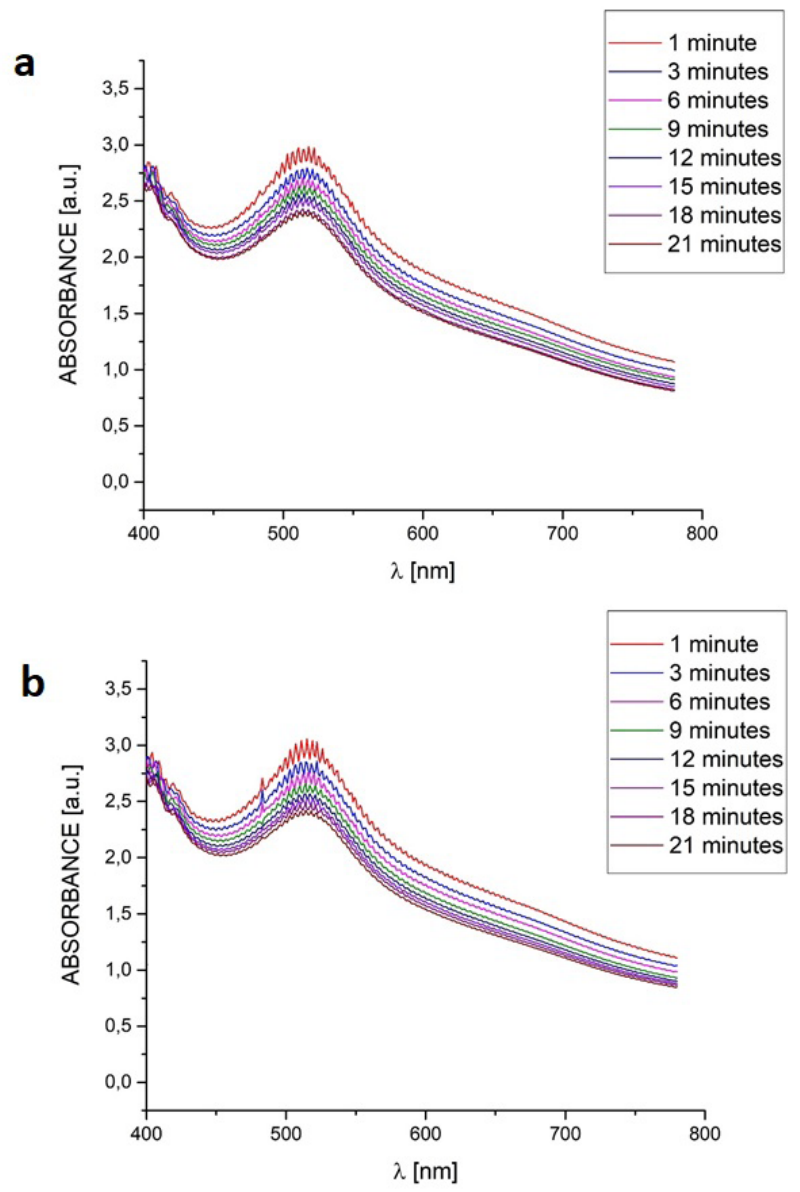

Figure 7: UV-Vis spectra of absorbance for DPPH interacting with (a) non-irradiated and (b) UV-irradiated nystatin. Times of interactions: 1, 3, 6, 9, 12, 15, 18 and $21 \mathrm{~min}$. $\lambda$ - wavelength.

taking to account in chose of the storage conditions of drug samples. ${ }^{30-32}$

\section{CONCLUSION}

The EPR and UV-Vis studies of the non-irradiated and UV-irradiated nystatin pointed out that:

1. Nystatin revealed the antioxidative character, because it quenched DPPH free radicals. The antioxidative character was observed for both non-irradiated and UV-irradiated nystatin.

2. Free radical scavenging activity decreased after UV-irradiation of nystatin, so this drug should not be exposed to ultraviolet electromagnetic waves during storage.

3. EPR spectroscopy and UV-Vis spectrophotometry are the useful methods to examination of the interactions of nystatin with DPPH and to determine the storage conditions of drug.
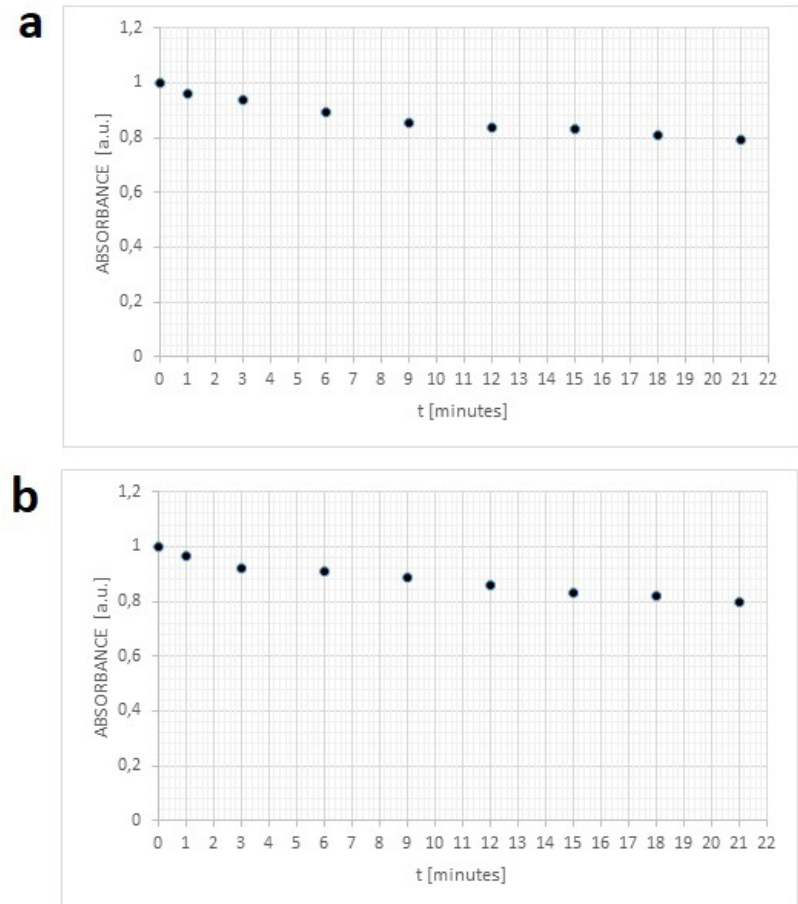

Figure 8: The influence of time (t) of interactions on the maximal absorbance of UV-Vis spectra of DPPH in contact with (a) non-irradiated and (b) UV-irradiated nystatin.

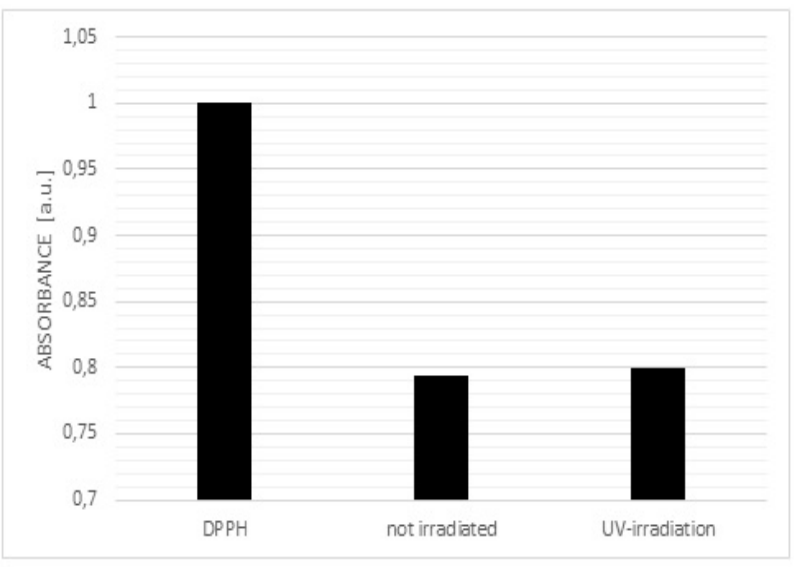

Figure 9: Comparison of the maximal absorbance of UV-Vis spectra of DPPH for DPPH and DPPH interacting with nonirradiated and UV-irradiated nystatin.

\section{ACKNOWLEDGEMENT}

This work was financially supported by Medical University of Silesia in Katowice, grant number: KNW$2-019 / \mathrm{K} / 6 / \mathrm{N}$.

\section{CONFLICT OF INTEREST}

The authors declare no conflict of interest. 


\section{ABBREVIATIONS}

EPR: Electron Paramagnetic Resonance Spectroscopy; DPPH: 2,2-difenyl- 1-picrylhydrazyl; UV: ultraviolet.

\section{REFERENCES}

1. Cadenas E, Packer L. Handbook of Antioxidants, Second Edition Revised and Expanded. New York, Basel: Marcel Dekker Inc. 2002.

2. Rosen P, Tritscheler HJ, King GA, Azzi A. Antioxidants in Diabetes Management. New York, Basel: CRC Press, Marcel Dekker Inc. 2002.

3. Rice-Evans CA, Packer L. Flavonoids in healts and disease. $2^{\text {nd }}$ ed. New York, Basel: Marcel Dekker Inc. 1998.

4. Krinsky NI, Mayne ST, Sies H. Carotenoids in Health and Disease. New York: Marcel Dekker Inc. 2004

5. Halliwell B, Gutteridge J. Free radicals in biology and medicine. $4^{\text {th }}$ ed. Oxford, New York: Oxford University Press. 2007.

6. Laher I. Systems Biology of Free radicals and Antioxidants. Berlin: Springer 2014.

7. Rani V, Yadav U. Free Radicals in Human Health and Disease. Berlin: Springer. 2014.

8. Pantopoulos K, Schipper HM. Principles of Free Radical Biomedicine, Biochemistry Research Trends. UK ed. New York: Nova Science Publishers. 2011.

9. Bartosz G. Druga TT. Wolne rodniki w przyrodzie. Warsaw: PWN. 2006.

10. Borgers M, Hay R, Rinaldi MG. Current Topics in medical Mycology. Berlin: Springer-Verlag. 2012.

11. Nucci M, Marr AK. Emerging Fungal Diseases. Clin Inf Diseases. 2005;41(4):521-6.

12. Kostowski W, Herman. SZ. Farmakologia. Warsaw: PZWL. 2007.

13. Janiec W, Krupińska J. Farmakodynamika. Warsaw: PZWL. 1999.

14. Wisman H, Smith C, Arnstein HRV, Halliwell B, Cannon M. The antioxidant action of ketoconazole and related azoles: comparison with tamoxifen and cholesterol. Chem-Biol Interact. 1991;79(2):229-43.

15. Kus C, Sozüdonmez F, Can-Eke B, Coban T. Antioxidant and antifungal properties of benzimidazole derivatives. Z Naturforsch. 2010;65(9-10):537-42.

16. Bors A, Niculae G, Stan R, Meghea A. Lipod nanocarriers with antifungal activity prepared by high pressure homogenization. Rev Chim (Bucharest). 2014;65(6):671-5.

17. Zejca A, Gorczyca M. Chemia leków. Warsaw: PZWL. 2004.

18. Rodino S, Butu M, Negoescu C, Caunii A, Cristina RT, Butnariu M. Spectrophotometric method for quantitative determination of nystatin antifungal agent in pharmaceutical formulations. Dig Nanomater Bios. 2014;9(3):1215-22.

19. Eaton GR, Eaton SS, Salikhov KM. Foundations of Modern EPR. Singapore: World Scientific. 1998.

20. Tirzitis G, Bartosz G. Determination of antiradical and antioxidant activity: basic principles and new insights. Acta Biochim Pol. 2010;57(1):139-442.

21. Molyneux P. The use of stable free radical diphenylpicrylhydrazyl (DPPH) for estimating antioxidant activity. Songklanakarin J Sci Technol. 2004;26(2):211-9.

22. Pyrzynska K, Pekal A. Application of free radical diphenylpicrylhydrazyl (DPPH) to estimate antioxidant capacity of food samples. Anal Methods. 2013;5(17):4288-95.

23. Padmanabhan $\mathrm{P}$, Jangle SN. Evaluation of DPPH Radical Scavenging Activity and Reducing Power of Four Selected Medicinal Plants and Their Combinations. Int J Pharm Sci Drug Res. 2012;4(2):143-6.

24. Wertz JE, Bolton JR. Electron Spin Resonance: Elementary Theory and Practical Application. New York, London: Chapman and Hall. 1986.

25. Stankowski J, Hilczer W. Wstęp do spektroskopii rezonansów magnetycznych. Warsaw: PWN. 2005.

26. Weil JA, Bolton JR. Electron Paramagnetic Resonance: Elementary Theory and Practical Applications. $2^{\text {nd }}$ Edition. New York: John Wiley and Sons. 2007.

27. Olczyk P, Komosińska-Vassev K, Ramos P, Mencer $Ł$, Olczyk K, Pilawa B. Interactions of short-acting, intermediate-acting and pre-mixed human insulins with free radicals - Comparative EPR examination. Intern J Pharm. 2015;490(1-2):9-15.

28. Komosińska-Vassev K, Olczyk P, Ramos P, Mencer $Ł$, Olczyk K, Pilawa B. Antioxidative properties of human insulin reference material and rapid-acting and long-acting insulin analog standards. Acta Pol Pharm. 2018;75(1):33-40.

29. Stanjek-Cichoracka A, Żegleń S, Ramos P, Pilawa B, Wojarski J. Effect of ultraviolet irradiation on free radical scavenging activity of immunosuppressants used in lung transplantation and comparative electron paramagnetic resonance study of kinetics of their interactions with model free radicals. J Clin Pharm Ther. 2018;43(3):385-92.

30. Ramos P, Pilawa B. Free radical formation in chloramphenicol heated at different temperatures and the best thermal sterilization conditions application of EPR spectroscopy and UV spectrophotometry. Pharm Dev Technol. 2016;1-9. DOI: 10.1080/10837450.2016.1265555.

31. Dołowy M, Ramos P, Pilawa B. Effect of UV irradiation and Temperature on Free Radical Properites in Dehydrocholix and Ursodeoxycholic Acid: An EPR Study. Int J Photoenergy. 2014. ID 953619: 1-7. DOI: 10.1155/2014/953619.

32. Ramos P, Pilawa B. Electron paramagnetic resonance examination of free radical formation in salicylic acid and urea exposed to UV irradiation. Int J Photoenergy. 2016. ID 7235305: 1-7. DOI: 10.1155/2016/7235305.

\section{SUMMARY}

- Free radicals are produced during the inflammatory process such as mycosis. The interactions with free radicals for nystatin applied in the mycosis accompanied by inflammation states are the important problem. The storage conditions affect the properties of the drug. The changes of the free radical scavenging activity of nystatin after UV-irradiation were examined. The EPR spectroscopy and UV-Vis spectrophotometry studies pointed out that nystatin revealed the antioxidative character, because it quenched DPPH free radicals. Free radical scavenging activity decreased after UV-irradiation of nystatin, so this drug should not be exposed to ultraviolet electromagnetic waves during storage. EPR spectroscopy and UV-Vis spectrophotometry are the useful methods to examination of the interactions of nystatin with DPPH and to determine the storage conditions of drug. 


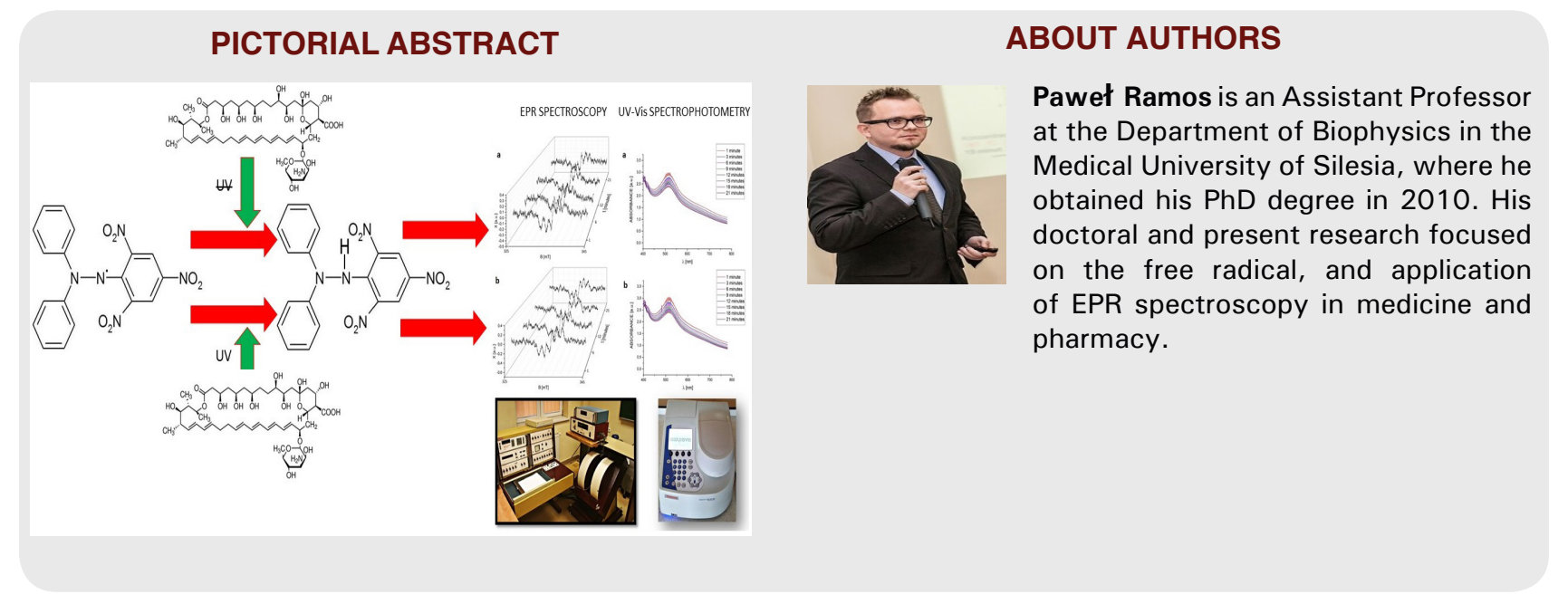

Cite this article: Ramos P, Pilawa B, Peplinski P. EPR and UV-Vis Spectroscopic Studies of the Influence of Ultraviolet Irradiation on Antioxidant Interactions of Nystatin. Indian J of Pharmaceutical Education and Research. $2019 ; 53(2 S):$ s186-s192. 